\title{
頭蓋内血管狭窄病変の遺伝的要因
}

\author{
宮脇 哲，齊藤 延人
}

東京大学医学部脳神経外科

\section{Genetic Factor for Intracranial Artery Stenosis}

\author{
Satoru Miyawaki M.D., Ph.D., and Nobuhito Saito, M.D., Ph.D. \\ Department of Neurosurgery, the University of Tokyo
}

Intracranial artery stenosis (ICAS), one of the major causes of ischemic stroke, has been suggested to have a genetic factor due to its high prevalence among Asians. We have identified a missense variant c.14429G > A (p.Arg4810Lys, rs112735431) of Ringer finger protein 213 (RNF213), which had originally been identified as a susceptibility genetic variant for moyamoya disease, to be significantly associated with ICAS. Furthermore, we conducted a comprehensive search for variants of RNF213 other than p. Arg4810Lys in ICAS. p.Arg4810Lys was the only variant that had a significant association with ICAS. Moreover, various rare variants of RNF213 were found in the ICAS cohort. Therefore, functional analysis of RNF213 is indispensable to clarify whether these rare variants are truly associated with the onset of ICAS. RNF213 p.Arg4810Lys has been shown to be associated not only with ICAS/moyamoya disease but also with coronary stenosis/renal artery stenosis and pulmonary hypertension. RNF213 p.Arg4810Lys has been attracting attention as a variant causing systemic vascular disease. Functional analysis of RNF213 is progressing, and known molecular cascades related to RNF213 expression regulation and cellular activity are gradually being clarified, but the mechanism involved in disease development has not yet been clarified and further analysis is expected.

(Received August 11, 2020 ; accepted August 19, 2020)

Key words : intracranial artery stenosis, genetic factor, RNF213

Jpn J Neurosurg (Tokyo) $29: 680-689,2020$

\section{はじめに}

頭蓋内血管狭窄（intracranial artery stenosis：ICAS）は 虚血性脳卒中の主要な原因の1つである。ICAS は高血 圧，糖尿病，脂質異常症といった生活習慣病を背景とし て頭蓋内血管に動脈硬化性の変化をきたし，血管狭窄内 腔が狭小化すると考元られ，その発症にはさまざまな後 天的要因が関与する多因子疾患と考元られる ${ }^{12)}$ 。一方で ICAS は有病率に集団差があり東アジア系集団やヒスパ ニック系集団やアフリカ系集団に多いことが知られてお
り, ICASの発症には何らかの遺伝的要因の関与が示唆 されてきた(4)1520)64)72).

多因子疾患に関わる遺伝的要因の探索として，全ゲノ 么領域関連解析研究 (genome wide association study: GWAS）というものが多くの疾患で行われてきている. GWAS とは全ゲノム領域に分布する遺伝的変異の頻度の 偏りを網羅的に検討する遺伝統計解析手法である ${ }^{55)}$. 脳 卒中においても遺伝的要因の探索としてGWASが行わ れてきており，脳卒中に関連するいくつかの一塩基多型 (single nucleotide polymorphism: SNP) が報告されてい

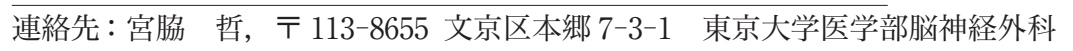

Address reprint requests to: Satoru Miyawaki, M.D., Department of Neurosurgery, the University of Tokyo, 7-3-1 Hongo, Bunkyo-ku, Tokyo 113-8655, Japan 


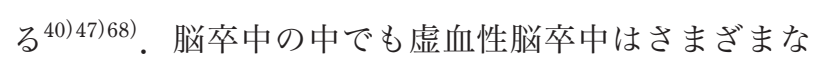
subtype に分かれることが知られており, 当然, 遺伝的 背景も異なると考えられる。これまで行われている虚血 性脳卒中に関する GWAS は, 古典的な TOAST 分類 ${ }^{2}$ に 準拠し, cardioembolic stroke, small-vessel stroke, largeartery stroke（LAS）の 3 分類に分けて sub 解析が行われ ている。しかしながら，こうした GWASを通じて ICAS に関する遺伝的要因の探索が十分行わ机ているとはいえ ない. TOAST 分類に基づく LAS には通常 ICASによる 脳梗塞のみならず, 頭蓋外の動脈狭窄 (extracranial artery stenosis：ECAS）による脳梗塞も含まれている2)。すなわ ち, ICASに限定した GWAS はこれまで行われていない.

ICAS の遺伝的要因の探索として, 単一の遺伝子レベ ルのSNPの解析がメインとして行われてきている ${ }^{44)}$.

ICAS に関わる遺伝的要因の候補として, adiponectin, $C 1 Q$ and collagen domain containing $(A D I P O Q)$ という遺 伝子の SNP である rs2241767 や apolipoprotein E (APOE) の $\varepsilon 4$ アレル, Phosphodiesterase 4D (PDE4D) の SNP で ある rs966221 などが報告されてきた ${ }^{13)}{ }^{25)}$.

われわれはもやもや病の疾患感受性遺伝子として同定 された ring finger protein 213 (RNF213）という遺伝子の ICAS と関連することを報告しさまざまな解析を行って きた. ICAS とRNF213に関する研究の現況と最新の知見 を報告する

\section{Ring finger protein 213 (RNF213)}

われわれはICAS の遺伝的要因の候補として RNF213 という遺伝子に着目して解析を行ってきた.

$R N F 213$ はもともともやもや病の疾患感受性遺伝子と して同定された遺伝子である。もやもや病とは, 両側の 内頝動脈終末部が慢性進行性に狭窄する頭蓋内動脈の狭 窄性を主たる病態として, 側副路として脳底部に異常血 管網（もやもや血管）が形成・発達することを特徵とす る脳血管疾患である $\left.{ }^{41} 58\right) 66$ )。もやもや病は, 家系内に多 く発症を認めることや日本をはじめとした東アジア系の 集団に多く発症を認めるという発症の集団差があること などから, 遺伝的要因の存在が長らく疑われてきた。 2011 年にもやもや病の感受性遺伝子の同定に関する報

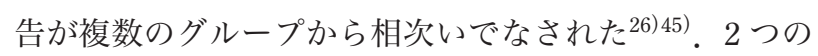
別のグループがそれぞれ異なる手法を用いて，17q25.3 に存在する RNF213を感受性遺伝子として同定した。 $R N F 213$ がコードするタンパク質は really interesting new gene (RING) finger ドメイン (遺伝子のC末側) と AAA ATPase ドメイン（遺伝子の中央部）を有して, E3 ユビ
キチンリガーゼと ATP 分解機能を有する新しい夕イプ のタンパク質である. RNF213の variant の中でも, ただ 1つの variantが日本をはじめとした東アジア系集団のも やもや病に強い関連があることが明らかとなった。その variant は, c.14429G >A (p.Arg4810Lys, rs112735431)（本 稿におけるRNF213 の reference sequence は現在の主流 の参照配列である National Center for Biotechnology Information Reference Sequence NM_001256071 NP_00124300 とする) である。このvariantにより $R N F 213$ の 4,810 番目のアミノ酸であるアルギニンがリ シンに変わる missense variantである. 日本人のもやも や病発症者の約 $80 \%$ この variant を有していることが 報告された。また日本人の $2 \%$ 程度がこの variant を有す ることが重要な点といえる ${ }^{46)}$.

その後もやもや病における RNF213 p.Arg4810Lys の解

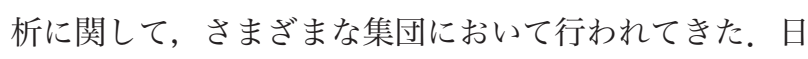
本以外に同じ東アジア系集団である韓国，中国において もやもや病との有意な関連が認められている ${ }^{43770)}$. 一方 で，ヨーロッパ系集団など東アジア系集団以外の集団に おいては, 一般人においても RNF213 p.Arg4810Lys はほ とんど認められず，もやもや病との関連も認められてい

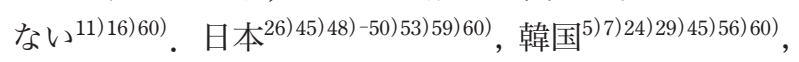
中国 ${ }^{23) 42(45) 60(69) 71) 73) 75)}$ における RNF213 p.Arg4810Lys の もやもや病の過去の報告をまとめたものを Table 1 に示 す. RNF213 p.Arg4810Lysのもやもや病患者と control に おける頻度は，日本と韓国においてはほぼ同等である が，中国においてはやや頻度が下がることが興味深い. 同じ東アジア系集団であっても，日本，韓国と中国とで はもやもや病の遺伝的背景が異なる可能性が示唆される.

\section{RNF213 とICAS}

われわれは, RNF213 p.Arg4810Lys がもやもや病のみ ならず，もやもや病と診断されない ICAS に関連する遺 伝的要因であるという仮説を立てて解析を行った.

もやもや病には厳格な診断基準が存在する ${ }^{76)}$. 簡潔に まとめると以下の 2 点を満たすことが条件である.

(1)内頝動脈の終末部の進行性の狭窄病変と側副血行路 としての大脳基底核におけるもやもや血管の発達を認め ること。

(2)動脈狭窄をきたす基礎疾患（染色体異常, 遺伝性疾 患, 炎症性疾患, 外傷, 腫瘍, 動脈硬化など) が存在し ないこと.

もやもや病診断基準の根本をなすのは画像所見および 除外診断であり, 実際の臨床の現場においては, もやも 
Table 1 Summary of the previous association studies of RNF213 p.Arg4810Lys and moyamoya disease

\begin{tabular}{|c|c|c|c|c|}
\hline & \multicolumn{2}{|c|}{ Rate of the carrier of $R N F 213$ p.Arg4810Lys } & \multirow{2}{*}{ Odds ratio $(95 \% \mathrm{CI})$} & \multirow{2}{*}{$\mathrm{p}$ value } \\
\hline & Case & Control & & \\
\hline $\begin{array}{l}\text { Japanese } \\
8 \text { reports }^{11) 18) 19) 25)-29)}\end{array}$ & $545 / 661(82.4 \%)$ & $40 / 1,459(2.7 \%)$ & $184.0(119.6-283.2)$ & $<0.0001^{*}$ \\
\hline $\begin{array}{l}\text { Korean } \\
7 \text { reports }^{19) 25) 30)-33) 35)}\end{array}$ & $657 / 922(71.2 \%)$ & $54 / 2,278(2.3 \%)$ & $109.7(76.3-157.9)$ & $<0.0001^{*}$ \\
\hline $\begin{array}{l}\text { Chinese } \\
7 \text { reports }^{19) 25) 34) 36)-40)}\end{array}$ & $461 / 2,081 \quad(22.1 \%)$ & $25 / 4,562(0.5 \%)$ & $51.6(34.3-77.5)$ & $<0.0001^{*}$ \\
\hline
\end{tabular}

${ }^{*}$ Statistically significant by Fisher exact test

Table 2 Summary of the previous association studies of RNF213 p.Arg4810Lys and ICAS

\begin{tabular}{|c|c|c|c|c|}
\hline & \multicolumn{2}{|c|}{ Rate of the carrier of $R N F 213$ p.Arg4810Lys } & \multirow{2}{*}{ Odds ratio $(95 \% \mathrm{CI})$} & \multirow{2}{*}{$\mathrm{p}$ value } \\
\hline & Case & Control & & \\
\hline $\begin{array}{l}\text { Japanese } \\
3 \text { reports }^{27)-29)}\end{array}$ & $39 / 229(17.0 \%)$ & $4 / 235(1.7 \%)$ & $11.8(4.16-33.7)$ & $<0.0001^{*}$ \\
\hline $\begin{array}{l}\text { Korean } \\
6 \text { reports }^{30) 32) 33) 42)-44)}\end{array}$ & $176 / 970(18.1 \%)$ & $75 / 2,938(2.5 \%)$ & $8.46(6.38-11.2)$ & $<0.0001^{*}$ \\
\hline $\begin{array}{l}\text { Chinese } \\
4 \text { reports }^{45)-48)}\end{array}$ & $27 / 1,570(1.7 \%)$ & $4 / 1,500(0.2 \%)$ & $6.54(2.28-18.74)$ & $<0.0001^{*}$ \\
\hline
\end{tabular}

${ }^{*}$ Statistically significant by Fisher exact test

や病と明確に診断することが困難な場合がある。特に高 齢者においては，頭蓋内動脈狭窄にある程度動脈硬化性 の変化を生じるため, 高齢になって偶発的に発見された 頭蓋内動脈の狭窄・閉塞病変はもやもや病なのか, 動脈 硬化性に生じているのかの鑑別がしばしば困難な場合が ある。われわれはさまざまな脳血管疾患における RNF213 p.Arg4810Lys の解析を通じて，もやもや病の診 断基準に該当しない，通常動脈硬化性と診断されるよう

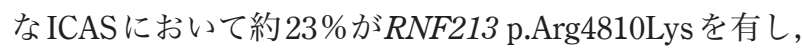
ICAS と RNF213 p.Arg4810Lys と有意に関連があること を明らかにした ${ }^{49) 50) 59)}$.

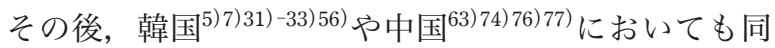
様の解析が行われ，ICAS と RNF213 p.Arg4810Lys との 有意な関連が示されている ${ }^{43)}$ 。これらの結果をまとめた ものを Table 2 に示す．もやもや病と同様に, RNF213 p.Arg4810Lys のも ICAS 患者と control における頻度は, 日本と韓国においてはほぼ同等であるが，中国において はやや頻度が下がることが興味深い.

RNF213 p.Arg4810Lys は日本, 韓国においては約 2\%, 中国では約 $1 \%$ に存在する一方で，ヨーロッパ系集団な ど他集団においてはほとんど認められないことが明らか となっており ${ }^{9)}$ ，この RNF213 p.Arg4810Lys variant の頻
度の差がもやもや病のみならず ICAS が東アジア系集団 において発症頻度が高いことを説明する遺伝的要因の 1 つと考えられる。

\section{ICAS と関連する p.Arg4810Lys 以外の RNF213 の variant の探索}

RNF213 は 17 番染色体長腕に存在し 5,207 のアミノ酸 からなる非常に大きなタンパク質を code する遺伝子で ある。日本人もやもや病のうち約 $20 \% の R N F 213$ p.Arg4810Lys を有しない症例やヨーロッパ系集団のもやも や病症例において, RNF213 上に p.Arg4810Lys 以外にも やもや病と関連する variant が存在しないかの検索がな されてきている27(37)44447)50)55162) 74)76)。 。机われは ICAS において RNF213 全体の解析を行って ICAS に関連する p.Arg4810Lys 以外の変異の探索を行った.

168 の ICAS と 1,194の control において次世代シーク エンサーを用いて RNF213 全体の解析を行った。このコ ホートにおいて $138 の$ nonsynonymous variant を認めた。 Case と controlにおいて, variant の頻度の差を統計学的 に検討する case control association study（関連解析）で は, p.Arg4810Lys のみが ICAS と有意な関連があった。 


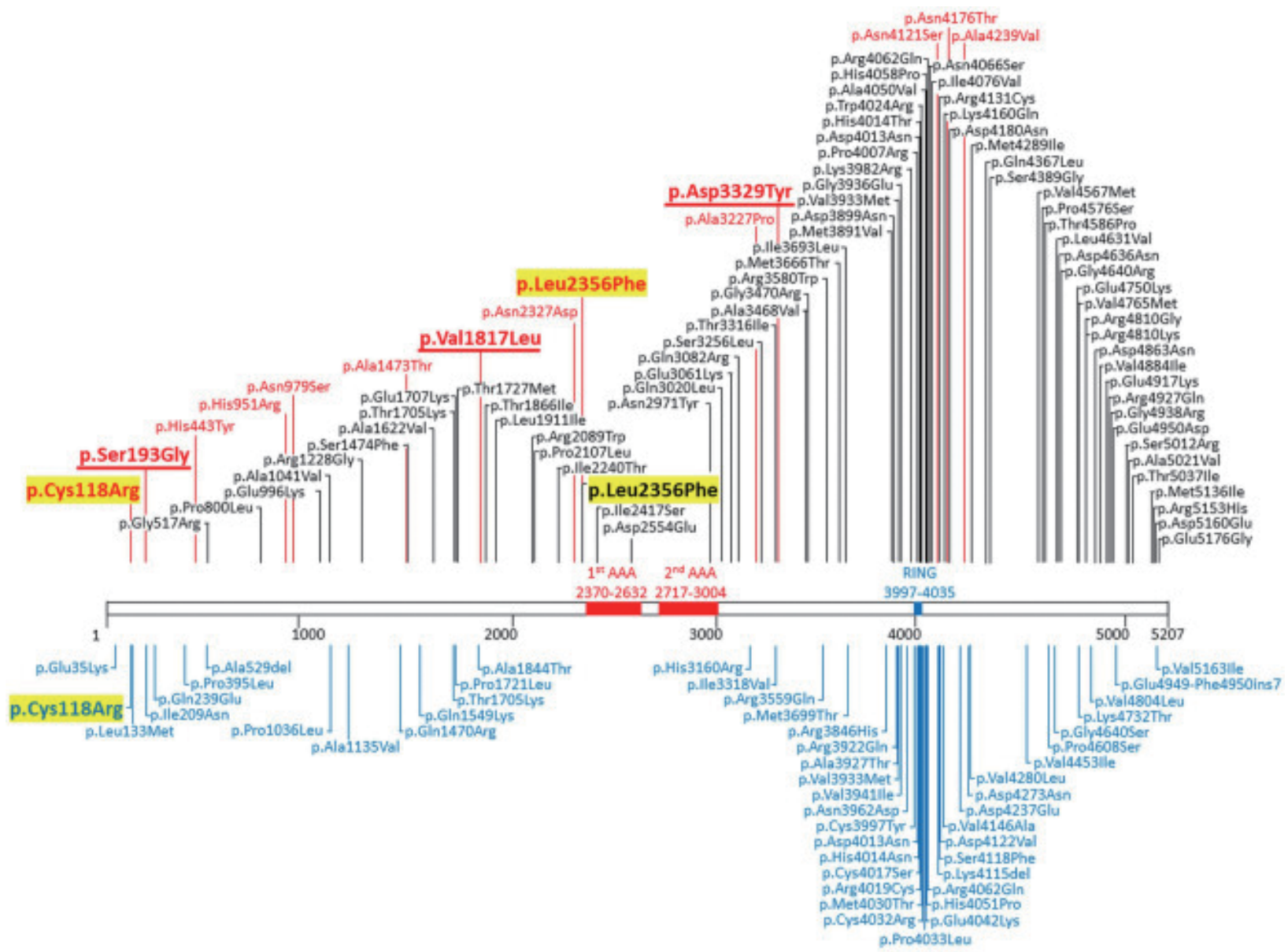

Fig. 1 RNF213 nonsynonymous rare variants found in patients with intracranial artery stenosis without p.Arg4810Lys and those with moyamoya disease (MMD) patients in previously reported studies. Variants found in the present study are marked in red, and previously reported RNF213 variants in patients with MMD in the Asian population and non-Asian populations are marked in black and blue, respectively. p.Cys118Arg and p.Leu2356Phe corresponded with two of the variants in patients with MMD. Variants p.Ser193Gly, p.Val1817Leu, and p.Asp3329Tyr were found neither in control subjects nor in the Single Nucleotide Polymorphism Database. (From reference 22)

RNF213 全体の解析からも p.Arg4810Lys の重要性が再確 認される結果となった ${ }^{22)}$.

また一般 populationにおいてきわめて頻度の低い rare variantについても検討をした。もやもや病の認められる rare variant は過去に多数報告されている。 それらを reviewして，今回のわれわれの ICAS でぬつかった rare variant と比較した(Fig. 1). p.Cys118Arg と p.Leu2356Phe は過去のもやもや病で報告のある rare variant で, ICAS との関連が示唆された。また p.Ser193Gly，p.Val1817Leu，p.Asp3329Tyrの3つは controlにも認められ ず,さらに Single Nucleotide Polymorphism Database (https://www.ncbi.nlm.nih.gov/snp/) にも報告がなく, 今回新規に同定された variantとして今後注視すべき variant である22).
こうした rare variant に関しては Polymorphism Phenotyping v2 (Polyphen2) や Combined Annotation Dependent Depletion (CADD) scoring などの in silicoでの pathogenicityの prediction はなされているもの, 実際のもやもや 病や ICAS 発症に関わっているかどうかに関しては機能 解析が必須である。しかしながら，もやもや病の RNF213 の遺伝子改変によるモデル生物が確立しておら ず，今後の課題である。ヨーロッパ系集団のもやもや病 の rare variant は一般 population と比して ring domain の 存在するRNF213 遺伝子の C 未側付近に有意に多く存在 することが報告され, ring domain を含めた $\mathrm{C}$ 末側の機能 異常がもやもや病の発症に関わっていることが示唆され ており，さらなる解析が期待される17)。今回われわれが ICAS において同定した rare variant は必ずしも C 末側に 
Table 3 Association study of RNF213 missense variants in patients with ICAS

\begin{tabular}{l|l|c|c|c|c}
\hline \multirow{2}{*}{ Variant } & \multirow{2}{*}{ rs ID } & \multicolumn{2}{|c|}{ Rate of the carrier of the variant } & \multirow{2}{*}{ Odds ratio $(95 \% \mathrm{CI})$} & \multirow{2}{*}{ p value } \\
\cline { 3 - 6 } & & Case & Control & & \\
\hline p.Arg4810Lys & rs112735431 & $41 / 168(23.2 \%)$ & $13 / 1,194(1.5 \%)$ & $29.3(15.3-56.2)$ & $1.5 \times 10^{-28 *}$ \\
p.Gln3082Arg & - & $2 / 168(1.1 \%)$ & $0 / 1,194(0 \%)$ & - & $1.51 \times 10^{-2}$ \\
p.Val1195Met & rs10782008 & $77 / 168(45.8 \%)$ & $665 / 1,194(55.6 \%)$ & $0.67(0.49-0.93)$ & $2.03 \times 10^{-2}$ \\
p.Pro61Leu & rs9913317 & $19 / 168(11.3 \%)$ & $74 / 1,194(6.1 \%)$ & $1.93(1.13-3.29)$ & $2.09 \times 10^{-2}$ \\
p.Ala1041Thr & rs61359568 & $5 / 168(2.9 \%)$ & $81 / 1,194(6.7 \%)$ & $0.42(0.17-1.06)$ & $2.59 \times 10^{-2}$ \\
\hline
\end{tabular}

* Statistically significant by Fisher exact test after the Bonferroni correction for multiple testing

(From reference 22)

集中しているわけではなく, RNF213 上の変異の位置の 違いが表現型の違いに影響を与えている可能性が示唆さ れる。

\section{RNF213 p.Arg4810Lys を 有する ICAS の特徵}

RNF213 p.Arg4810Lys を有する ICAS の特徵として, 狭窄部位において血管の外径が小さくなっている negative remodeling を起こしていること年21)，また狭窄の部 位は椎骨動脈や脳底動脈といった後方循環系の血管に比 して内頝動脈や中大脳動脈といった前方循環の動脈狭窄 において多いことが報告されている27)3359). またもやも や病と同様に女性の頻度が高いことも報告されている ${ }^{27)}$.

内頝動脈などの前方循環の動脈の血管平滑筋は発生学 的に neural crest由来であることに対し, 椎骨脳底動脈と いった後方循環の動脈の血管平滑筋は中肧葉由来である ことが知られている ${ }^{3839)}$. こうした発生学的な背景の違 いが，RNF213 変異によって血管狭窄を起こしやすい部 位との関わりをもっている可能性がある.

また韓国のグループから RNF213 p.Arg4810Lys を有す るもやもや病・ICAS は長期の follow up で脳梗塞の再発 のリスク因子であると報告されている30).さらなる大規 模な解析が期待される.

\section{全身の血管疾患と RNF213 p.Arg4810Lys}

最近この RNF213 p.Arg4810Lys は，日本人において一 般の脳卒中のリスクとなっていることも報告され ${ }^{54)}$ ，日 本人にとって重要な脳血管疾患関連の遺伝的要因の 1 つ と考えられている。

また RNF213 p.Arg4810Lys は頭蓋内の動脈狭窄のみな らず全身の血管との関連が明らかとなってきている。腎 動脈狭窄や冠動脈狭窄, 肺動脈狭窄とも関連があること
が報告されている6)1118)51)。また RNF213 p.Arg4810Lys は肺高血圧症とも関連することが報告されてい る ${ }^{14) 3665)}$ ，さらに注目すべきは，RNF213 p.Arg4810Lys を有する肺高血圧症は予後が不良であることが報告さ れ ${ }^{19)}$ ，こうした症例に対しては早期の肺移植を考慮すべ きと考えられ，肺高血圧症の治療に扮ける precision medicine の可能性が示唆されている。このように RNF213 p.Arg4810Lys は全身の血管疾患をきたす variant として注目され始めている.

\section{RNF213 の機能解析}

先に述べたように RNF213 は 17 番染色体長腕に存在 し 5,207のアミノ酸からなるタンパク質を code する遺伝 子である26)45)。RNF213 のタンパク質は really interesting new gene (RING) finger ドメインとAAA ATPase ドメイ ンを有して，E3 ユビキチンリガーゼと ATP 分解機能を 有する新しい夕イプのタンパク質である ${ }^{26) 45)}$. RNF213 p.R4810K variant は in vitro の血管内皮細胞レベルでは， 血管新生能が低下しており何かしらの機能障害をきたす ことが報告されているが37)，in vivoでのノックアウト， ノックインマウスにおいては脳血管には異常をきたすこ とはなく, RNF213 の異常単独では血管病変を生じるこ とない28)61)。その一方で変異を強制発現したマウスに対 して低酸素負荷をかけると血管新生が抑制されるという 報告もあり ${ }^{52)}$ ，血管病変発症には別の因子が必要である ことが示唆されている. RNF213 の発現調節や細胞活性 に関連する既知の分子カスケード (INF $\beta$ やWNT signal) も徐々に明らかとなってきている ${ }^{34) 57)}$ 。また細胞内の脂 質代謝に関わることも明らかになってきている ${ }^{62)}$. 最 近，マウスに拈いてクライオ電子顕微鏡を用いてRNF213 のタンパク質の構造が明らかになった ${ }^{3)}$. C 末端側に存 在するもやもや病関連の variant が dominant negative に 働き RNF213 の E3 ユビキチンリガーゼとしては機能を 
全般的に低下させることが報告され, RNF213の $\mathrm{E} 3$ ユビ キチンリガーゼとしての機能低下がもやもや病・ICAS の発症に関与していることが示唆されている8). しかし ながら RNF213 およびその変異がヒトの頭蓋内の動脈狭 窄を生じる正確なメカニズムは明らかとなっておらず, さらなる解析が求められる。

\section{今後の展望と課題}

RNF213 は ICAS やもやもや病のみならず全身の血管 疾患と関連する遺伝子として注目され始めている. RNF213 p.Arg4810Lys は日本人の $2 \%$ が有することから， 日本人にとって重要な遺伝子 variant である。一方で RNF213 p.Arg4810Lys を有するすべての人が疾患を発症 するわけではなく, 疾患の発症にはさらに別の要因が必 要と考元られ，そうした要因の同定が今後の課題であ る. RNF213のさらなる機能解析の発展も不可欠である.

著者全員は日本脳神経外科学会への COI 自己申告の登録を 完了しています。本論文に関して開示すべき COI はありませ h.

\section{文 献}

1) Abboud $S$, Viri LE, Lutjohann $D$, Goebeler $S$, Luoto T, Friedrichs S, Desfontaines P, Gazagnes MD, Laloux P, Peeters A, Seeldrayers P, Lehtimaki T, Karhunen P, Pandolfo M, Laaksonen R: Associations of apolipoprotein E gene with ischemic stroke and intracranial atherosclerosis. Eur J Hum Genet 16:955-960, 2008.

2) Adams HP Jr, Bendixen BH, Kappelle LJ, Biller J, Love BB, Gordon DL, Marsh EE 3rd: Classification of subtype of acute ischemic stroke. Definitions for use in a multicenter clinical trial. TOAST. Trial of Org 10172 in Acute Stroke Treatment. Stroke 24:35-41, 1993.

3) Ahel J, Lehner A, Vogel A, Schleiffer A, Meinhart A, Haselbach D, Clausen T: Moyamoya disease factor RNF213 is a giant E3 ligase with a dynein-like core and a distinct ubiquitin-transfer mechanism. Elife 9: e56185, 2020.

4) Banerjee C, Chimowitz MI : Stroke caused by atherosclerosis of the major intracranial arteries. Circ Res 120:502513, 2017.

5) Bang OY, Chung JW, Cha J, Lee MJ, Yeon JY, Ki CS, Jeon P, Kim JS, Hong SC : A polymorphism in RNF213 is a susceptibility gene for intracranial atherosclerosis. PLoS One 11: e0156607, 2016.

6) Bang OY, Chung JW, Kim DH, Won HH, Yeon JY, Ki CS, Shin HJ, Kim JS, Hong SC, Kim DK, Koizumi A : Moyamoya disease and spectrums of RNF213 vasculopathy. Transl Stroke Res 11: 580-589, 2020.

7) Bang OY, Ryoo S, Kim SJ, Yoon CH, Cha J, Yeon JY, Kim KH, Kim GM, Chung CS, Lee KH, Shin HJ, Ki CS, Jeon P, Kim JS, Hong SC : Adult moyamoya disease : A burden of intracranial stenosis in East Asians? PLoS One 10: e0130663,
2015.

8) Bhardwaj A, Banh RS, Zhang W, Sidhu SS, Neel BG : Moyamoya disease-associated RNF213 alleles encode dominant negative alleles that globally impair ubiquitylation. bioRxiv 2020.

9) Cao Y, Kobayashi H, Morimoto T, Kabata R, Harada KH, Koizumi A : Frequency of RNF213 p.R4810K, a susceptibility variant for moyamoya disease, and health characteristics of carriers in the Japanese population. Environ Health Prev Med 21: 387-390, 2016.

10) Cecchi AC, Guo D, Ren Z, Flynn K, Santos-Cortez RL, Leal SM, Wang GT, Regalado ES, Steinberg GK, Shendure J, Bamshad MJ, Grotta JC, Nickerson DA, Pannu H, Milewicz $\mathrm{DM}$ : RNF213 rare variants in an ethnically diverse population with Moyamoya disease. Stroke $\quad 45: 3200-3207,2014$.

11) Chang SA, Song JS, Park TK, Yang JH, Kwon WC, Kim SR, Kim SM, Cha J, Jang SY, Cho YS, Kim TJ, Bang OY, Song JY, Ki CS, Kim DK : Nonsyndromic peripheral pulmonary artery stenosis is associated with homozygosity of RNF213

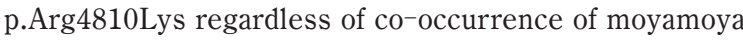
disease. Chest 153: 404-413, 2018.

12) Choi EH, Lee H, Chung JW, Seo WK, Kim GM, Ki CS, Kim $\mathrm{YC}$, Bang OY : Ring finger protein 213 variant and plaque characteristics, vascular remodeling, and hemodynamics in patients with intracranial atherosclerotic stroke: A highresolution magnetic resonance imaging and hemodynamic study. J Am Heart Assoc $\quad$ 8: e011996, 2019.

13) Cui M, Zhou S, Li R, Yin Z, Yu M, Zhou H : Association of ADIPOQ single nucleotide polymorphisms with the risk of intracranial atherosclerosis. Int J Neurosci 127 : 427-432, 2017.

14) Fukushima $H$, Takenouchi $T$, Kosaki $K$ : Homozygosity for moyamoya disease risk allele leads to moyamoya disease with extracranial systemic and pulmonary vasculopathy. $A m$ J Med Genet A $\quad 170$ : 2453-2456, 2016.

15) Gorelick PB, Wong KS, Bae HJ, Pandey DK : Large artery intracranial occlusive disease : a large worldwide burden but a relatively neglected frontier. Stroke $\mathbf{3 9}: 2396-2399$, 2008.

16) Grami N, Chong M, Lali R, Mohammadi-Shemirani P, Henshall DE, Rannikmae K, Pare G : Global assessment of mendelian stroke genetic prevalence in 101635 individuals from 7 ethnic groups. Stroke $\quad \mathbf{5 1}:$ 1290-1293, 2020.

17) Guey S, Kraemer M, Herve D, Ludwig T, Kossorotoff M, Bergametti F, Schwitalla JC, Choi S, Broseus L, Callebaut I, Genin E, Tournier-Lasserve E ; FLEX consortium : Rare RNF213 variants in the C-terminal region encompassing the RING-finger domain are associated with moyamoya angiopathy in Caucasians. Eur J Hum Genet $25: 995-1003$, 2017.

18) Hara $S$, Shimizu $K$, Nariai T, Kishino M, Kudo T, Umemoto $T$, Inaji M, Maehara $\mathrm{T}$ : De novo renal artery stenosis developed in initially normal renal arteries during the long-term follow-up of patients with moyamoya disease. J Stroke Cerebrovasc Dis 29: 104786, 2020.

19) Hiraide $T$, Kataoka M, Suzuki H, Aimi $Y$, Chiba T, Isobe $S$, Katsumata Y, Goto S, Kanekura K, Yamada Y, Moriyama H, Kitakata H, Endo J, Yuasa S, Arai Y, Hirose N, Satoh T, Hakamata Y, Sano M, Gamou S, Kosaki K, Fukuda K : Poor outcomes in carriers of the RNF213 variant (p.Arg4810Lys) with pulmonary arterial hypertension. J Heart Lung Transplant 39 : 103-112, 2020. 
20) Holmstedt CA, Turan TN, Chimowitz MI : Atherosclerotic intracranial arterial stenosis : risk factors, diagnosis, and treatment. Lancet Neurol 12:1106-1114, 2013.

21) Hongo H, Miyawaki S, Imai H, Shinya Y, Ono H, Mori H, Nakatomi H, Kunimatsu A, Saito N : Smaller outer diameter of atherosclerotic middle cerebral artery associated with RNF213 c.14576G $>$ A variant (rs112735431). Surg Neurol Int $8: 104,2017$.

22) Hongo H, Miyawaki S, Imai H, Shimizu M, Yagi S, Mitsui J, Ishiura H, Yoshimura J, Doi K, Qu W, Teranishi Y, Okano A, Ono H, Nakatomi H, Shimizu T, Morishita S, Tsuji S, Saito $\mathrm{N}$ : Comprehensive investigation of RNF213 nonsynonymous variants associated with intracranial artery stenosis. SciRep 10: 11942, 2020.

23) Huang Y, Cheng D, Zhang J, Zhao W : Association between the rs112735431 polymorphism of the RNF213 gene and moyamoya disease : A case-control study and meta-analysis. J Clin Neurosci $32:$ 14-18, 2016.

24) Jang MA, Chung JW, Yeon JY, Kim JS, Hong SC, Bang OY, Ki CS : Frequency and significance of rare RNF213 variants in patients with adult moyamoya disease. PLoS One 12 : e0179689, 2017.

25) Kalita J, Somarajan BI, Kumar B, Kumar S, Mittal B, Misra UK : Phosphodiesterase $4 \mathrm{D}$ gene polymorphism in relation to intracranial and extracranial atherosclerosis in ischemic stroke. Dis Markers $31:$ 191-197, 2011.

26) Kamada F, Aoki Y, Narisawa A, Abe Y, Komatsuzaki S, Kikuchi A, Kanno J, Niihori T, Ono M, Ishii N, Owada Y, Fujimura M, Mashimo Y, Suzuki Y, Hata A, Tsuchiya S, Tominaga T, Matsubara Y, Kure S: A genome-wide association study identifies RNF213 as the first Moyamoya disease gene. $J$ Hum Genet $\mathbf{5 6}: 34-40,2011$.

27) Kamimura T, Okazaki S, Morimoto T, Kobayashi H, Harada K, Tomita T, Higashiyama A, Yoshimoto T, Takahashi JC, Nakagawara J, Koga M, Toyoda K, Maruyama H, Koizumi A, Ihara M : Prevalence of RNF213 p.R4810K variant in earlyonset stroke with intracranial arterial stenosis. Stroke 50 : 1561-1563, 2019.

28) Kanoke A, Fujimura M, Niizuma K, Ito A, Sakata H, SatoMaeda M, Morita-Fujimura Y, Kure S, Tominaga T : Temporal profile of the vascular anatomy evaluated by 9.4 -tesla magnetic resonance angiography and histological analysis in mice with the R4859K mutation of RNF213, the susceptibility gene for moyamoya disease. Brain Res $\quad 1624: 497-505$, 2015.

29) Kim EH, Yum MS, Ra YS, Park JB, Ahn JS, Kim GH, Goo HW, Ko TS, Yoo HW : Importance of RNF213 polymorphism on clinical features and long-term outcome in moyamoya disease. J Neurosurg 124: 1221-1227, 2016.

30) Kim HJ, Choi EH, Chung JW, Kim JH, Kim YS, Seo WK, Kim GM, Bang OY : Luminal and wall changes in intracranial arterial lesions for predicting stroke occurrence. Stroke 51:2495-2504, 2020.

31) Kim J, Park YS, Woo MH, An HJ, Kim JO, Park HS, Ryu CS, Kim OJ, Kim NK : Distribution of intracranial major artery stenosis/occlusion according to RNF213 polymorphisms. Int J Mol Sci 21: 1956, 2020.

32) Kim YJ, Lee JK, Ahn SH, Kim BJ, Kang DW, Kim JS, Kwon $\mathrm{SU}$ : Nonatheroscleotic isolated middle cerebral artery disease may be early manifestation of moyamoya disease. Stroke 47:2229-2235, 2016.

33) Kim YJ, Kim BJ, Lee MH, Lee HB, Lee JS, Chang DI, Choi-
Kwon S, Chun S, Lee JK, Kang DW, Kwon SU, Kim JS : Are genetic variants associated with the location of cerebral arterial lesions in stroke patients? Cerebrovasc Dis 49 : 262-268, 2020.

34) Kobayashi H, Matsuda Y, Hitomi T, Okuda H, Shioi H, Matsuda T, Imai H, Sone M, Taura D, Harada KH, Habu T, Takagi Y, Miyamoto S, Koizumi A : Biochemical and functional characterization of RNF213（Mysterin） R4810K, a susceptibility mutation of moyamoya disease, in angiogenesis in vitro and in vivo. J Am Heart Assoc 4: e002146, 2015.

35) Kobayashi H, Brozman M, Kyselova K, Viszlayova D, Morimoto T, Roubec M, Skoloudik D, Petrovicova A, Juskanic D, Strauss J, Halaj M, Kurray P, Hranai M, Harada KH, Inoue S, Yoshida Y, Habu T, Herzig R, Youssefian S, Koizumi A : RNF213 rare variants in Slovakian and Czech moyamoya disease patients. PLoS One 11: e0164759, 2016.

36) Kobayashi H, Kabata R, Kinoshita H, Morimoto T, Ono K, Takeda M, Choi J, Okuda H, Liu W, Harada KH, Kimura T, Youssefian S, Koizumi A : Rare variants in RNF213, a susceptibility gene for moyamoya disease, are found in patients with pulmonary hypertension and aggravate hypoxiainduced pulmonary hypertension in mice. Pulm Circ 8: $2045894018778155,2018$.

37) Koizumi A, Kobayashi H, Hitomi T, Harada KH, Habu T, Youssefian S: A new horizon of moyamoya disease and associated health risks explored through RNF213. Environ Health Prev Med 21 : 55-70, 2016.

38) Komiyama $\mathrm{M}$ : Cardio-cephalic neural crest syndrome : A novel hypothesis of vascular neurocristopathy. Interv Neuroradiol 23: 572-576, 2017.

39) Komiyama $M:$ RNF213 genetic variant and the arterial circle of Willis. J Stroke Cerebrovasc Dis 27 : 2892-2893, 2018.

40) Kubo M, Hata J, Ninomiya T, Matsuda K, Yonemoto K, Nakano T, Matsushita T, Yamazaki K, Ohnishi Y, Saito S, Kitazono T, Ibayashi S, Sueishi K, Iida M, Nakamura Y, Kiyohara Y : A nonsynonymous SNP in PRKCH (protein kinase $\mathrm{C}$ eta) increases the risk of cerebral infarction. Nat Genet 39: 212-217, 2007.

41) Kuroda S, Houkin K : Moyamoya disease : current concepts and future perspectives. Lancet Neurol $7: 1056-1066$, 2008.

42) Lee MJ, Chen YF, Fan PC, Wang KC, Wang K, Wang J, Kuo MF : Mutation genotypes of RNF213 gene from moyamoya patients in Taiwan. J Neurol Sci 353: 161-165, 2015.

43) Liao X, Deng J, Dai W, Zhang T, Yan J: Rare variants of RNF213 and moyamoya/non-moyamoya intracranial artery stenosis/occlusion disease risk: a meta-analysis and systematic review. Environ Health Prev Med 22: 75, 2017.

44) Liu M, Gutierrez J : Genetic risk factors of intracranial atherosclerosis. Curr Atheroscler Rep 22: 13, 2020.

45) Liu W, Morito D, Takashima S, Mineharu Y, Kobayashi H, Hitomi T, Hashikata H, Matsuura N, Yamazaki S, Toyoda A, Kikuta K, Takagi Y, Harada KH, Fujiyama A, Herzig R, Krischek B, Zou L, Kim JE, Kitakaze M, Miyamoto S, Nagata K, Hashimoto N, Koizumi A : Identification of RNF213 as a susceptibility gene for moyamoya disease and its possible role in vascular development. PLoS One 6 : e22542, 2011.

46) Liu W, Hitomi T, Kobayashi H, Harada KH, Koizumi A : Distribution of moyamoya disease susceptibility polymorphism p.R4810K in RNF213 in East and Southeast Asian populations. Neurol Med Chir (Tokyo) $52:$ 299-303, 2012. 
47) Malik R, Chauhan G, Traylor M, Sargurupremraj M, Okada Y, Mishra A, Rutten-Jacobs L, Giese AK, van der Laan SW, Gretarsdottir S, Anderson CD, Chong M, Adams HHH, Ago T, Almgren P, Amouyel P, Ay H, Bartz TM, Benavente OR, Bevan S, Boncoraglio GB, Brown RD Jr, Butterworth AS, Carrera C, Carty CL, Chasman DI, Chen WM, Cole JW, Correa A, Cotlarciuc I, Cruchaga C, Danesh J, de Bakker PIW, DeStefano AL, den Hoed M, Duan Q, Engelter ST, Falcone GJ, Gottesman RF, Grewal RP, Gudnason V, Gustafsson S, Haessler J, Harris TB, Hassan A, Havulinna AS, Heckbert SR, Holliday EG, Howard G, Hsu FC, Hyacinth HI, Ikram MA, Ingelsson E, Irvin MR, Jian X, Jiménez-Conde J, Johnson JA, Jukema JW, Kanai M, Keene KL, Kissela BM, Kleindorfer DO, Kooperberg C, Kubo M, Lange LA, Langefeld CD, Langenberg C, Launer LJ, Lee JM, Lemmens R, Leys $\mathrm{D}$, Lewis CM, Lin WY, Lindgren AG, Lorentzen E, Magnusson PK, Maguire J, Manichaikul A, McArdle PF, Meschia JF, Mitchell BD, Mosley TH, Nalls MA, Ninomiya T, O’Donnell MJ, Psaty BM, Pulit SL, Rannikmäe K, Reiner AP, Rexrode KM, Rice K, Rich SS, Ridker PM, Rost NS, Rothwell PM, Rotter JI, Rundek T, Sacco RL, Sakaue S, Sale MM, Salomaa V, Sapkota BR, Schmidt R, Schmidt CO, Schminke U, Sharma P, Slowik A, Sudlow CLM, Tanislav C, Tatlisumak T, Taylor KD, Thijs VNS, Thorleifsson G, Thorsteinsdottir U, Tiedt S, Trompet S, Tzourio C, van Duijn CM, Walters M, Wareham NJ, Wassertheil-Smoller S, Wilson JG, Wiggins KL, Yang Q, Yusuf S ; AFGen Consortium ; Cohorts for Heart and Aging Research in Genomic Epidemiology (CHARGE) Consortium ; International Genomics of Blood Pressure (iGEN-BP) Consortium; INVENT Consortium; STARNET, Bis JC, Pastinen T, Ruusalepp A, Schadt EE, Koplev S, Björkegren JLM, Codoni V, Civelek M, Smith NL, Trégouët DA, Christophersen IE, Roselli C, Lubitz SA, Ellinor PT, Tai ES, Kooner JS, Kato N, He J, van der Harst P, Elliott P, Chambers JC, Takeuchi F, Johnson AD ; BioBank Japan Cooperative Hospital Group ; COMPASS Consortium ; EPIC-CVD Consortium ; EPIC-InterAct Consortium ; International Stroke Genetics Consortium (ISGC) ; METASTROKE Consortium ; Neurology Working Group of the CHARGE Consortium ; NINDS Stroke Genetics Network (SiGN) ; UK Young Lacunar DNA Study ; MEGASTROKE Consortium, Sanghera DK, Melander O, Jern C, Strbian D, Fernandez-Cadenas I, Longstreth WT Jr, Rolfs A, Hata J, Woo D, Rosand J, Pare G, Hopewell JC, Saleheen D, Stefansson K, Worrall BB, Kittner SJ, Seshadri S, Fornage M, Markus HS, Howson JMM, Kamatani Y, Debette S, Dichgans $\mathrm{M}$ : Multiancestry genome-wide association study of 520,000 subjects identifies 32 loci associated with stroke and stroke subtypes. Nat Genet $\quad \mathbf{5 0}: 524-537,2018$.

48) Miyatake S, Miyake N, Touho H, Nishimura-Tadaki A, Kondo Y, Okada I, Tsurusaki Y, Doi H, Sakai H, Saitsu H, Shimojima K, Yamamoto T, Higurashi M, Kawahara N, Kawauchi H, Nagasaka K, Okamoto N, Mori T, Koyano S, Kuroiwa Y, Taguri M, Morita S, Matsubara Y, Kure S, Matsumoto $\mathrm{N}$ : Homozygous c.14576G $>$ A variant of RNF213 predicts early-onset and severe form of moyamoya disease. Neurology 78: 803-810, 2012.

49) Miyawaki S, Imai H, Takayanagi S, Mukasa A, Nakatomi H, Saito N : Identification of a genetic variant common to moyamoya disease and intracranial major artery stenosis/occlusion. Stroke $43: 3371-3374,2012$.

50) Miyawaki S, Imai H, Shimizu M, Yagi S, Ono H, Mukasa A,
Nakatomi H, Shimizu T, Saito N : Genetic variant RNF213 c. $14576 \mathrm{G}>\mathrm{A}$ in various phenotypes of intracranial major artery stenosis/occlusion. Stroke $\quad 44: 2894-2897,2013$.

51) Morimoto T, Mineharu Y, Ono K, Nakatochi M, Ichihara S, Kabata R, Takagi Y, Cao Y, Zhao L, Kobayashi H, Harada KH, Takenaka K, Funaki T, Yokota M, Matsubara T, Yamamoto K, Izawa H, Kimura T, Miyamoto S, Koizumi A : Significant association of RNF213 p.R4810K, a moyamoya susceptibility variant, with coronary artery disease. PLoS One 12: e0175649, 2017.

52) Morimoto T, Enmi JI, Hattori Y, Iguchi S, Saito S, Harada KH, Okuda H, Mineharu Y, Takagi Y, Youssefian S, Iida H, Miyamoto S, Ihara M, Kobayashi H, Koizumi A : Dysregulation of RNF213 promotes cerebral hypoperfusion. Sci Rep 8 : 3607, 2018.

53) Moteki Y, Onda H, Kasuya H, Yoneyama T, Okada Y, Hirota K, Mukawa M, Nariai T, Mitani S, Akagawa H : Systematic validation of RNF213 coding variants in Japanese patients with moyamoya disease. J Am Heart Assoc 4: e001862, 2015.

54) Okazaki S, Morimoto T, Kamatani Y, Kamimura T, Kobayashi H, Harada K, Tomita T, Higashiyama A, Takahashi JC, Nakagawara J, Koga M, Toyoda K, Washida K, Saito S, Takahashi A, Hirata M, Matsuda K, Mochizuki H, Chong M, Pare G, O’Donnell M, Ago T, Hata J, Ninomiya T, Dichgans M, Debette S, Kubo M, Koizumi A, Ihara M : Moyamoya disease susceptibility variant RNF213 p.R4810K increases the risk of ischemic stroke attributable to large-artery atherosclerosis. Circulation 139: 295-298, 2019.

55) Ozaki K, Ohnishi Y, lida A, Sekine A, Yamada R, Tsunoda T, Sato H, Sato H, Hori M, Nakamura Y, Tanaka T : Functional SNPs in the lymphotoxin-alpha gene that are associated with susceptibility to myocardial infarction. Nat Genet 32: 650-654, 2002.

56) Park MG, Shin JH, Lee SW, Park HR, Park KP : RNF213 rs112735431 polymorphism in intracranial artery stenoocclusive disease and moyamoya disease in Koreans. J Neurol Sci $375:$ 331-334, 2017.

57) Scholz B, Korn C, Wojtarowicz J, Mogler C, Augustin I, Boutros M, Niehrs C, Augustin HG : Endothelial RSPO3 controls vascular stability and pruning through $\mathrm{Non}^{-}$canonical WNT/Ca $(2+) /$ NFAT signaling. Dev Cell $\quad 36: 79-93$, 2016.

58) Scott RM, Smith ER : Moyamoya disease and moyamoya syndrome. N Engl J Med 360: 1226-1237, 2009.

59) Shinya $Y$, Miyawaki S, Imai H, Hongo H, Ono H, Takenobu A, Nakatomi H, Teraoka A, Saito N : Genetic analysis of ring finger protein 213 (RNF213) c.14576G $>$ A in intracranial atherosclerosis of the anterior and posterior circulations. $J$ Stroke Cerebrovasc Dis 26 : 2638-2644, 2017.

60) Shoemaker LD, Clark MJ, Patwardhan A, Chandratillake G, Garcia S, Chen R, Morgan AA, Leng N, Kirk S, Chen R, Cook DJ, Snyder M, Steinberg GK: Disease variant landscape of a large multiethnic population of moyamoya patients by Exome Sequencing. G3 (Bethesda) 6:41-49, 2015.

61) Sonobe S, Fujimura M, Niizuma K, Fujimura T, Furudate S, Nishijima Y, Kure S, Tominaga T : Increased vascular MMP9 in mice lacking RNF213 : moyamoya disease susceptibility gene. Neuroreport 25:1442-1446, 2014.

62) Sugihara M, Morito D, Ainuki S, Hirano Y, Ogino K, Kitamura A, Hirata H, Nagata K : The AAA + ATPase/ubiquitin 
ligase mysterin stabilizes cytoplasmic lipid droplets, J Cell Biol 218: 949-960, 2019.

63) Sun X, Luo M, Li J, Lai R, Lin J, Wang Y, Xu X, Wu S, Sheng $\mathrm{W}$ : Prevalence of RNF213 variants in symptomatic intracranial arterial stenosis/occlusion in China. Mol Genet Genomics 295:635-643, 2020.

64) Suri MFK, Zhou J, Qiao Y, Chu H, Qureshi AI, Mosley T, Gottesman RF, Wruck L, Sharrett AR, Alonso A, Wasserman BA : Cognitive impairment and intracranial atherosclerotic stenosis in general population. Neurology $\quad 90$ : e1240e1247, 2018.

65) Suzuki H, Kataoka M, Hiraide T, Aimi Y, Yamada Y, Katsumata Y, Chiba T, Kanekura K, Isobe S, Sato Y, Satoh T, Gamou S, Fukuda K, Kosaki K: Genomic comparison with supercentenarians identifies RNF213 as a risk gene for pulmonary arterial hypertension. Circ Genom Precis Med 11: e002317, 2018.

66) Suzuki J, Takaku A : Cerebrovascular "moyamoya” disease. Disease showing abnormal net-like vessels in base of brain. Arch Neurol 20 : 288-299, 1969.

67）富永悌二，鈴木則宏，宮本 享，小泉昭夫，黒田 敏, 高橋 淳, 藤村 幹, 寶金清博: 厚生労働科学研究費補 助金難治性疾患克服事業ウイリス動脈輪閉塞症における 病態・治療に関する研究班：もやもや病（ウイリス動脈 輪閉塞症) 診断・治療ガイドライン (改訂版)。脳卒中の 外科 46:1-24, 2018 .

68) Traylor M, Farrall M, Holliday EG, Sudlow C, Hopewell JC, Cheng YC, Fornage M, Ikram MA, Malik R, Bevan S, Thorsteinsdottir U, Nalls MA, Longstreth W, Wiggins KL, Yadav S, Parati EA, Destefano AL, Worrall BB, Kittner SJ, Khan MS, Reiner AP, Helgadottir A, Achterberg S, FernandezCadenas I, Abboud S, Schmidt R, Walters M, Chen WM, Ringelstein EB, O’Donnell M, Ho WK, Pera J, Lemmens R, Norrving B, Higgins P, Benn M, Sale M, Kuhlenbäumer G, Doney AS, Vicente AM, Delavaran H, Algra A, Davies G, Oliveira SA, Palmer CN, Deary I, Schmidt H, Pandolfo M, Montaner J, Carty C, de Bakker PI, Kostulas K, Ferro JM, van Zuydam NR, Valdimarsson E, Nordestgaard BG, Lindgren A, Thijs V, Slowik A, Saleheen D, Paré G, Berger K, Thorleifsson G ; Australian Stroke Genetics Collaborative, Wellcome Trust Case Control Consortium 2 (WTCCC2), Hofman A, Mosley TH, Mitchell BD, Furie K, Clarke R, Levi C, Seshadri S, Gschwendtner A, Boncoraglio GB, Sharma P, Bis JC, Gretarsdottir S, Psaty BM, Rothwell PM, Rosand J, Meschia JF, Stefansson K, Dichgans M, Markus HS ; International Stroke Genetics Consortium: Genetic risk factors for ischaemic stroke and its subtypes (the
METASTROKE collaboration): a meta-analysis of genome-wide association studies. Lancet Neurol 11 : 951962, 2012.

69) Wang X, Zhang Z, Liu W, Xiong Y, Sun W, Huang X, Jiang Y, Ni G, Sun W, Zhou L, Wu L, Zhu W, Li H, Liu X, Xu G: Impacts and interactions of PDGFRB, MMP-3, TIMP-2, and RNF213 polymorphisms on the risk of Moyamoya disease in Han Chinese human subjects. Gene 526: 437-442, 2013.

70) Wang X, Wang Y, Nie F, Li Q, Zhang K, Liu M, Yang L, Zhang Q, Liu S, Zeng F, Shang M, Liang M, Yang Y, Liu X, Liu W : Association of genetic variants with moyamoya disease in 13000 individuals : A meta-analysis. Stroke 51:1647$1655,2020$.

71) Wang Y, Zhang Z, Wei L, Zhang Q, Zou Z, Yang L, Li D, Shang M, Han C, Mambiya M, Bao X, Li Q, Hao F, Zhang K, Wang H, Liu S, Liu M, Zeng F, Nie F, Wang K, Liu W, Duan L: Predictive role of heterozygous p.R4810K of RNF213 in the phenotype of Chinese moyamoya disease. Neurology $\mathbf{9 4}$ : e678-e686, 2020.

72) White H, Boden-Albala B, Wang C, Elkind MS, Rundek T, Wright CB, Sacco RL : Ischemic stroke subtype incidence among whites, blacks, and Hispanics : the Northern Manhattan Study. Circulation 111: 1327-1331, 2005.

73) Wu Z, Jiang H, Zhang L, Xu X, Zhang X, Kang Z, Song D, Zhang J, Guan M, Gu Y : Molecular analysis of RNF213 gene for moyamoya disease in the Chinese Han population. PLoS One 7: e48179, 2012.

74) Xue S, Cheng W, Wang W, Song X, Wu J, Song H : The association between the ring finger protein 213 gene R4810K variant and intracranial major artery stenosis/occlusion in the Han Chinese population and high-resolution magnetic resonance imaging findings. Brain Circ $\quad 4: 33-39,2018$.

75) Zhang Q, Liu Y, Zhang D, Wang R, Zhang Y, Wang S, Yu L, Lu C, Liu F, Zhou J, Zhang X, Zhao J : RNF213 as the major susceptibility gene for Chinese patients with moyamoya disease and its clinical relevance. J Neurosurg 126:11061113, 2017.

76) Zhang Q, Yu L, Ge P, Ma Y, Zhang D, Zhang Y, Wang R, Wang S, Zhao Y, Cao Y, Liu X, Deng X, Zhao J : Association of ring finger protein 213 Gene P.R4810k polymorphism with intracranial major artery stenosis/occlusion. J Stroke Cerebrovasc Dis $27: 1556-1564,2018$.

77) Zhang T, Guo C, Liao X, Xia J, Wang X, Deng J, Yan J : Genetic analysis of RNF213 p.R4810K variant in non-moyamoya intracranial artery stenosis/occlusion disease in a Chinese population. Environ Health Prev Med 22: 41, 2017. 


\section{頭蓋内血管狭窄病変の遺伝的要因}

\section{宮脇 哲 齊藤 延人}

Ringer finger protein 213 (RNF213) の missense variant c.14429G>A (p.Arg4810Lys, rs112735431）が頭蓋内血管狭窄（intracranial artery stenosis：ICAS）と有意な関連があることが明 らかにされてきた. また RNF213 p.Arg4810Lys は, 冠動脈狭窄・腎動脈狭窄や肺高血圧症との関連 が明らかとなっており, 全身の血管疾患をきたす variant として注目されてきている. RNF213 の機能 解析も進んでいるが, 疾患発症に関わるメカニズムはいまだ明らかとなっておらず, さらなる解析が 期待される。 